\title{
Suggestions on Teaching Reform of Theory of Machines and Mechanisms
}

\author{
Qiang Liu \\ College of Mechanic Engineering \\ Hubei University of Automotive Technology \\ Shiyan, Hubei Province 442002, P.R. China \\ 435807721@qq.com
}

\author{
Hongxia Wang \\ College of Mechanic Engineering \\ Hubei University of Automotive Technology \\ Shiyan, Hubei Province 442002, P.R. China \\ 168269057@qq.com
}

\begin{abstract}
There are many problems in the teaching of mechanical principles. For example, the content of the textbooks is outdated, the learning time is reduced, the teaching theory is out of touch with practice, the student-to-faculty ratio is small and the method of assessing students is backward. These problems seriously affect and restrict the teaching and learning of mechanical principles. The teaching reform of mechanical principle is imperative. As for the problems, the article put forward some suggestions for reform. The suggestions are to build "WeChat" public teaching materials, to integrate teaching content, to build "micro-class", to participate in mechanical innovation competition, to accelerate the construction of software and hardware of the school, to develop a comprehensive evaluation system for students. This requires the participation of teachers and students and related units. Only in this way can the reform of mechanical principles be carried out smoothly.
\end{abstract}

Keywords-theory of machines and mechanisms; teaching reform; micro-course teaching method; innovation competition

\section{INTRODUCTION}

Theory of machines and mechanisms is the main course of mechanical. It plays a certain role in the nexus of major study. But in the teaching process of theory of machines and mechanisms, teachers generally focus on teaching basic knowledge of the principles, kinematics and dynamics analysis of the mechanisms. Although the teacher explains them thoroughly, students' autonomous learning ability is not strong and positive. The knowledge points of theory of machines and mechanisms are abstract and students have no perceptual knowledge of some mechanisms, so they are often unable to grasp them quickly. Causing problems left behind, accumulating more problems and the classroom efficiency is low. Combining our school conditions and based on years of teaching experience, teaching reform of theory of machines and mechanisms is urgently required.

\section{MAIN PROBLEMS}

\section{A. The teaching materials are old}

Most of the current theory of machines and mechanisms textbooks have been reprinted many times, while basic content is just simple version of previous versions or slightly modified and the content of textbook become obsolete[1]. For example,

This work was supported by the items of educational research of Hube Automotive Industries Institute (JX201618); Natural Science Fund of Hubei Province (2017CFB741) the mechanism motion and force analysis, used to be limited by computer technology, a graphical method is adopted. It is simple and intuitive but it can only analyze movement and force at a particular location of the mechanisms. The motion and force of the entire motion cycle cannot be analyzed. The efficiency and the accuracy are low and it is sill as the course key explanation. Today, computer technology is mature. Artificial intelligence is in full swing. Therefore, the introduction and application of three - dimensional drawing software and dynamic software analysis should be included in the textbook of theory of machines and mechanisms,for example, solid works simulation module analysis mechanism movement and adams dynamics software analysis mechanism force. The application of computer software can analyze the movement and force of the whole cycle of the mechanisms. Not only the efficiency is high but also the precision is high. The text should also increase the content of generalized mechanism and space mechanism. This is the era of mechatronics. The pure machinery has been unable to meet the actual production needs.

Theory of machines and mechanisms is a professional basic course. It is more versatile. But the teaching material expression way is relatively simple and content is boring. Examples cannot be well combined with professional and practical life. Many examples of machine tools, fixtures and mechatronics can be used in mechanical manufacturing. Many examples of cars can be used in vehicle engineering. It can also give more examples of life, for example, the children's toys, the fitness equipment in the community, etc. This will stimulate students' enthusiasm for learning and interest in reading.

The content of the textbook cannot be well connected with other course content. The teaching material content is abstract and difficult to understand. Students who are more diligent may look through relevant textbooks. But most of them couldn't. Because of some the concepts are not clear and it is difficult to understand the course content and learning efficiency is low. Therefore, the relevant course content should be briefly introduced in the following sections. Remove some learning disabilities for students and it can work twice as much. 


\section{B. The class hours are reduced}

With the rapid development of computer technology and high speed and precision machinery, the teaching requirements and contents of theory of machines and mechanisms course have changed greatly. More emphasis on analytical analysis of mechanism movement and the project design of mechanism. Knowledge about robots is also increased. But class hours of theory of machines and mechanisms are reduced to 56 hours from the original 64 hours now and teaching content is unchanged. In order to complete the teaching plan, teachers are almost cramming education and leave no time for independent thinking of students. Theory of machines and mechanisms is a course that pays attention to design practices. This cramming education is contrary to quality education. How the teaching effectiveness of theory of machines and mechanisms can be ensured. Foundation is not good and not to talk about other courses study.

\section{The theory is out of practice}

The course of theory of machines and mechanisms uses multimedia to assist teaching. In the courseware there are also many application examples and animations of theory of machines and mechanisms. Restricted by teaching hours, students have no practical application concepts of mechanism in life and production. These instances are not well connected with theoretical knowledge. This results in the disconnection between theory teaching and engineering practice.

\section{Student-faculty ratios are small}

With the expansion of college enrolment, the number of students increases dramatically while the number of teachers increases slowly. From the previous a small classroom of 3040 students to now a big classroom of hundreds of students, while the teacher is one teacher and the faculty student ratio is small. This affects the classroom teaching and management seriously. Students do not listen to lectures and talk about other things in the class. After class, they would like to plagiarize the homework. Teachers communicate with students very little and they don't understand students. How can teachers know students' learning difficulties? How can teaching and learning benefit each other? If this kind of situation continues and it is bound to affect teachers' teaching and the students' learning.

\section{E. Assessment method is backward}

Assessment method of theory of machines and mechanisms has been used for decades. It is still made of regular grades and experimental grades. Students still stay in the time that just to pass and everything is all right. The present cannot compare with the past. It takes a fancy to a person's operational capability and actual application ability in modern society. Now most of the students try to learn and deal with a few of previous test papers before the exams and often are able to pass the exam. But pass the exam means noting. Many students even don't understand what some professional terms of theory of machines and mechanisms mean. When they join in work, how much they will think of and how much they can use. It is obviously that assessment methods lag behind and can't urge the students' learning and growing.

\section{SUGGESTIONS}

For the problems above, the suggestions of teaching reform are put forward:

\section{A. WeChat public teaching materials are built}

With the full coverage of wireless wifi in colleges and universities nationwide and the overall popularity of smartphones, in the form of the WeChat scan code, which is popular with college students and the textbook is ready to be written[2]. Many universities have a course website or a course center for theory of machines and mechanisms,but limited to website speed and not easy to access. Therefore, theory of machines and mechanisms WeChat, which is easy to carry and refer to, was born. The publishing house can cooperate with excellent teachers in key universities. The difficult formula, problem solving and basic concepts in the textbook of theory of machines and mechanisms are recorded in the corresponding micro video to the public platform. Students can see the teacher's explanation at any time by scanning the code. Learning is more targeted. Without the accumulation of problems and the difficulty of learning is reduced. You can also make a video of a complex mechanism in the textbook or an actual mechanism in your life and release it to the platform. Students can watch it multiple times. Thus, the movement and composition of the mechanism are more intuitive. In addition, the content of the course related to theory of machines and mechanisms can be published to the public number. In this way, the content of theory of machines and mechanisms is more substantial, richer and becomes three-dimensional and that can stimulate students' interest in learning and enthusiasm. At the same time, through WeChat public platform we can also release the latest development of theory of machines and mechanisms at home and abroad. Timely update the content of the textbook to keep pace with the times. Let the theory of machines and mechanisms teaching material to be able to live in real time with the production life.

\section{B. Teaching contents are integrated}

In view of the class hours are compressed, the teaching content of mechanical principle should be integrated[3]. The key points and difficulties should be highlighted. The basic concepts, basic theories and basic methods can be understood and mastered by using simple and effective graphic method. In particular the basic methods, namely, enlarging component, the equivalent mechanism, the reverse rotation, etc should be mastered. On the basis of mastering the basic methods students' ability of mathematical modeling and computer programming to solve practical problems is cultivated gradually through big assignments and course design. This will solve the problem of less class hours and more contents.

At the same time, the class hours of a subject should depend on the content of the textbook, the instruction of the teachers and the ability of the students to accept it. On this basis the coordination problem with other disciplines is considered. The administrative department of the school shall, in accordance with the actual situation, formulate the number of hours for the course. Due to the expansion of university enrollment and the quality of college students has generally 
declined. It is difficult to master the fundamentals of theory of machines and mechanisms in a short period of 56 class hours. To lay a good foundation for future professional courses and it is recommended to increase the number of class hours from 56 to 64 .

\section{Micro-course teaching method is introduced in teaching}

Theory of machines and mechanisms are more logical and many knowledge points are difficult to understand and remember. Traditional teaching methods emphasize commonality and disregard individuality.

The teaching idea of "Learn in doing, do in learning" cannot be embodied. Students are often passive to accept the knowledge. This not only inhibits students' interest in learning, but also teachers feel physically and mentally exhausted during the teaching process. It affects the classroom atmosphere. In order to develop students' subjective initiative, cultivate students' interest in learning and improve their learning ability, micro-course teaching method is introduced in teaching. With the help of the internet and multimedia, some difficult, abstract and complex knowledge points are integrated and summarized and play them in a short video. This increases the interest of the course and arouses the student's learning enthusiasm. Students study independently on the internet in their spare time. It can make up for what the teacher failed to explain in class because of the reduction in class hours.

\section{Mechanical design innovation competition is carried out}

In order to cultivate students' practical and innovation ability, the school holds innovative design competitions regularly[4]. The school holds an annual innovation program competition and an innovative design competition is held every two years. The excellent works of the competition are organized to participate in the national college students mechanical innovation design competition. Through the competition, students can get the full training from discovering problems, analyzing problems, solving problems to model making and even prototype making. Thus, the students have the preliminary ability of mechanical motion scheme design. It cultivates students' innovative consciousness and innovation ability. Students' creative enthusiasm and potential are stimulated. Students' desire for knowledge and creativity are motivated. The excellent talents stand out from the crowd. A number of innovative projects with engineering value are produced.

\section{E. The construction of software and hardware of school should be accelerated}

Since the enrollment expansion of colleges and universities, the number of students increased dramatically. But the corresponding hardware and software construction of school has not kept pace. First is the shortage of teachers and one teacher to hundreds of students in class is a common phenomenon. In face of hundreds of students, the teacher wants to communicate with each student good enough is difficult. Although foreign also has big classroom, a professor teaching and four to five assistants helping in the classroom and there is also a fixed laboratory for teachers and students to communicate. But the teacher is not easy to introduce. It relates to the current policy. On the one hand is that requirement of teachers is particularly high and on the other hand is that treatment and welfare of teachers is quite low. The two contradictory aspects happen to teachers at the same time. Therefore, many talented people are willing to do other jobs and not a teacher. Student-faculty ratios are badly affected. In the current condition of school buildings are shortage and teachers on the front is less, student-faculty ratios are better to be controlled within the scope of $1 / 20 \sim 1 / 40$. In order to enter into this scope, the school should bring more talents or reduce enrollment amount appropriately. The development of higher education is to the direction of small class in the world. Our school should be in this direction.

\section{F. A comprehensive examination of student should be made}

In terms of evaluation we can draw lessons from German universities. When a course is over, the master teacher will decorate a comprehensive exercise problem on this course for each student. Let students access to massive amounts of data to carry on the design. Then students find teachers to reply. Students modify papers according to the revisions. Then find teachers reply again and modify papers until all teachers are satisfaction. The advantage of this method is that students are examined synthetically. At the same time, design capacity and practical ability are improved and also social ability is exercised. Combined the practice of German universities and according to the actual situation of our school, other subject teachers in mechanical major should involve in the examination of theory of machines and mechanisms, too. Students are examined from different aspects and students' comprehensive capacity is also exercised and cultivated.

\section{CONCLUSION}

From summarizing the problems in theory of machines and mechanisms teaching, it is not difficult to find out that the problems influence each other. For example, the construction of teaching material will affect the teaching hours and at the same time it will affect the teachers' teaching and students' learning. Class hours reduce or increase will affect the selection and editing of teaching materials. Construction of school buildings will affect the introduction of teachers and enrollment of students. In turn, the introduction of teachers and enrollment of students will put forward higher requirements to school building construction. The changing of the methods of assessment will put forward higher requirements to the comprehensive quality of teachers. Teachers' comprehensive quality and number will affect the content and methods of assessment. Therefore, teaching reform of theory of machines and mechanisms is a systematic project. Just change one thing or one person alone, a certain organization can't solve the problems, it needs concerted efforts of various aspects and there is a possibility of success.

\section{REFERENCES}

[1] H.Sun, Z.M.Chen, W.J.Ge, Theory of Machines and Mechanisms, 8th ed., Higher Education Press, Beijing,2013 (In Chinese) 
[2] L.L.Long, "Multi-media serial textbooks for mechanisms theory and machine Design,” J. Machine Design and Research. Vol.19, No.2,pp.7172, April 2003 (In Chinese)

[3] J.Zhao,S.S.Wei, "The practice of teaching reform of mechanical principle course,”J. Higher Education in Chemical Engineering. NO.1,pp.14-16, January 2007 (In Chinese)

[4] P.Li, "Discussion on teaching reform and practice on practicum in mechanical theory course,” J. Chongqing Technical Business Univ. Vol. 32 ,NO.3, pp.100-102, March 2015 (In Chinese)
[5] D.Guo, "Analysis of the number of higher education teachers in China from the perspective of student-faculty ratios," J. HENAN SOCIAL SCIENCES. Vol.22 No.8, pp.97-101, Aug. 2014 (In Chinese)

[6] D.S.Li, "Teaching reform and practice for mechanical theory in applied undergraduate colleges,”J. Journal of HuaiHai Institute of Technology. Vol.10, NO.3,PP.90-92,Feb.2012 (In Chinese) 